\title{
ОСОБЕННОСТИ ПРОЦЕССОВ КОНЦЕНТРАЦИИ И ЦЕНТРАЛИЗАЦИИ НА РЫНКЕ БАНКОВСКИХ УСЛУГ
}

\author{
(C) 2020 Коновалова Мария Евгеньевна \\ доктор экономических наук, заведующий кафедрой экономической теории \\ Самарский государственный экономический университет, Россия, Самара \\ E-mail:mkonoval@mail.ru
}

В статье рассмотрены процессы централизации и концентрации капитала, происходящие в настоящее время на рынке банковских услуг. Выявлены положительные и отрицательные последствия концентрации капитала, в частности, усиление монополизации банковского сектора. Отмечена роль институтов системы страхования вкладов, а именно АСВ и ФКБС как основных регуляторов процедуры санации кредитных организаций. Сделан вывод о необходимости поддержания конкуренции на рынке банковских услуг за счет развития сети региональных банков.

Ключевые слова: банковский сектор, конкуренция, монополизация банковского сегмента, АСВ, ФКБС, централизация, концентрация капитала, санация, банкротство.

В общем смысле, централизация - понятие, подразумевающее объединение нескольких объектов под руководством единого центра. Данное понятие применяется во многих сферах: политической, экономической, социологической и т.д. Рассмотрим это понятие более конкретно, с экономической стороны, а именно как централизацию капитала. Это рост размера капитала путем различных форм его реорганизаций.

Централизация капитала происходит на основе процесса концентрации и представляет собой слияние существующих капиталов.

Развитие и становление централизации вовсе не зависит от увеличения общественного капитала, что является ключевым отличием данного процесса от процесса концентрации. Централизация же имеет свойство совершаться путем простого изменения в распределении уже имеющихся капиталов. Концентрация выступает процессом, который определяет развитие перехода от частных к общественным формам собственности. Именно на нее опирается централизация. По сути, централизация - важная часть процесса концентрации. Это именно тот этап, на котором совершается качественный скачок, который позволяет извлечь весь эффект предшествующего длительного количественного роста производительных сил. Можно сказать, что централизация доводит дело концентрации до конца. Исторически процесс централизации берет свое начало с образования акционерных обществ, ведь они давали возможность их основателям мобилизовать и подчинять более мел- кие капиталы. Этот процесс происходит в условиях ожесточенной конкуренции, как в форме поглощения крупными капиталами более мелких, так и посредством образования АО. По мнению Е.Ф.Борисова, такая форма экономики, как акционерная, позволила кардинально преобразить организационные масштабы производственного капитала [1]. Именно она дала толчок к увеличению концентрации производства. На основе больших заводов появилась и централизация экономики, которая может выражаться в следующих формах:

1. горизонтальной - происходит объединение компаний одной отрасли;

2. вертикальной - объединение предприятий различных технологических ступеней;

3. диагональной - объединение предприятий разных отраслей, которые не связаны между собой технологически. Таким образом, возникают конгломераты, задача которых - уменьшить риск банкротства, а убытки одних подразделений компенсируются прибылями других.

Развитие акционерных форм и функционирование акционерного капитала [5] привело к значительным изменениям в распределении национального дохода, а также послужило созданию новых инструментов накопления капитала и распределении дохода. Итогом таких процессов стало снижение имущественного неравенства в странах с развитой рыночной экономикой, значительный рост производства, и как следствие, увеличение средних слоев населения. Именно акционерная форма выступило инстру- 
ментом для создания особого канала финансирования предпринимательской деятельности экономики. Такая форма выступает механизмом распределения доходов и непосредственно изменение социальной структуры общества. Ведь, как известно, акционера приобретают права на участие в управлении компании, а само участие определяется размером пакета акций. Стоит отметить, что вместе с развитием акционерной формы, произошли кардинальные изменения и во взаимоотношениях государства и бизнеса. Постепенно заметно появление новой разновидности $\mathrm{AO}$, как государственные акционерные общества. Ключевым отличием такой разновидности заключается в том, что в данном случае государство выступает субъектом экономических отношений на равных правах с другими субъектами, и соответственно, имеет равные права с ними. Важным аспектом является и то, что именно прибыль компании является источником для выплаты дивидендов. Следовательно, у компании появляется стимул для накопления собственного капитала и для использования этого капитала эффективнее. А за счет результативной деятельности самой компании может быть реализована предпочитаемая доходность акций.

Так, можно сказать, что акционерная форма общества является наиболее эффективной формой предпринимательской деятельности с точки зрения возможности аккумулировать определенные денежные средства.

Хочется отметить, что до 20-го века процесс централизации капитала в основном происходил по горизонтали, т.е. компании главным образом объединялись в своих отраслях. В период после первой мировой войны возникла уже тенденция к вертикальной централизации капитала, а именно предприятия непосредственно объединялись или приобретали компании, деятельность которых не была связанна с компанией-покупателем [2]. А после 1945 года в наиболее развитых странах наблюдалось становление банковских монополий, которое сложилось в результате усиленной активизации процессов слияний и поглощений. Такие монополии, можно сказать, что «захватили» контроль над многими финансовыми институтами, помимо того, они монополизировали и денежный рынок - подчинили себе все свободные денежные сбережения населения.

В пятидесятых годах замечается достаточно быстрое развитие новой формы процесса централизации капитала, а именно диверсификация. Интеграция и диверсификация происходили благодаря накоплениям внутри самих фирм и в результате слияний и поглощений сторонних предприятий. Например, в 50-х годах заметно в большей степени, что крупные компании производят поглощение более мелких, а в следующем десятилетии преобладало уже поглощение и средних, и крупных фирм, имевшие многоотраслевой характер. В это же время, помимо банковских монопольных объединений, возникают и объединения промышленности, которые тоже имели непосредственно монополистический характер. Такие структуры охватывали другие сферы материального производства, таким образом, происходил процесс преобразования в достаточно сложный многоотраслевой организм.

В 60-70 года появляется усиление процессов концентрации и централизации капитала, которое было вызвано наличием потребностей капиталистического производства в процессе развитии научно-технической революции, а потом и расширением международных отношений в хозяйственном плане, и появлением конгломератов.

По мере увеличения доли капитала промышленных компаний, крупные банки определяют целевое направление капиталов, полученные в результате накоплении прибыли и различных вкладов. В начале семидесятых годов сложились международные банковские объединения [6]. Данное проявление было вызвано появлением необходимости в немедленной мобилизации значительных денежных сумм в различных валютах, обеспечении ускорения различных банковских операций, а также вмешательства банковского капитала в деятельность промышленного капитала.

Концентрация финансово-экономической власти в руках банков и рост международных банковских ассоциаций, это все означает новую, более высокую стадию социализации производства, нарастание конкурентной борьбы среди отдельных объединений монополистического капитала и расширение привлечения рабочей силы. По мере расширения производства и накопления, усовершенствуются конкуренция и кредит, выступающие одними из наиболее значимых рычагов централизации. Следовательно, можно отметить, что эти два понятия так или иначе обусловлены определенным уровнем 
накопления. В результате концентрации появляются некие изменения в формах частной собственности, а затем, и в формах самой конкуренции и кредита. Ведь, действительно, процесс сосредоточения капиталов приводит к монополии и, как следствие, к монополистической конкуренции.

Отметим, что централизация капитала возрастает в результате конкурентной борьбы между производителями. Ведь такая конкуренция конвоируется разорением и исключением мелких и средних игроков с рынка. В такой ситуации, централизация осуществляется путем поглощения много мелких капиталов, преобразуя их в несколько более крупные. Но помимо конкурентной борьбы процесс централизации происходит и при другом вспомогательном рычаге, который выступает в форме кредита. Ведь, сам кредит - это достаточно мощное орудие в конкуренции, который оборачивается в огромный социальный механизм преимущественно для централизации капитала. На основе кредита появляется новая форма предприятия, которое оказывает значительное влияние на кардинальное изменение системы капиталистического общества в целом. А именно, такой новой формой выступает акционерное общество.

Также, стоит заметить, что развитию процесса централизации способствует развитый рынок ценных бумаг [7]. Именно приобретение голосующих акций и владение контрольным пакетом акций компании дают возможность устанавливать и увеличивать управление и контроль над множеством предприятий, находящихся в различных регионах страны, из одного центра. С помощью централизации можно объединить капиталы нескольких фирм для решения каких-то важных и значимых вопросов и аккумулировать денежные средства для реализации финансирования конкретных программ. Она лежит в основе создания холдинговых и материнско-зависимых систем, что служит единственным направлением создания промышленно-финансовых групп, выступающим ядром любой национальной экономики. Ключевое преимущество от создания больших интегрированных структур выступает в значимости объединения капитала в различных сферах предприятия. Достаточно часто на основе слияния различных компаний можно придти к операционной экономии. Происходит устранение одинаковых функций работников, например, в сфере маркетинга или учета. Дости- жение такой экономии известно как синергизм, стоимость компаний, образовавшихся в результате слияния, превышает сумму стоимостей ее составляющих частей. В дополнение к операционной экономии, слияние может привести к экономии за счет «эффекта масштаба», т.е. когда происходит увеличение выпуска и продаж продукции компании.

Результатом процесса централизации выступает и контроль над ценами на рынке, способный усиливаться в процессе конкуренции производителей. Отметим, что процесс централизации усиливается при ликвидации крупными игроками тех игроков, которые не согласны с условиями монополистов, нежели при конкуренции между крупными и мелкими игроками на рынке

Осуществить данный процесс на практике достаточно сложно, применяя при этом достаточное количество взаимосвязанных мероприятий. Именно от решения специалистов по организации и проведении слияния или поглощения зависит дальнейшие возможности компании в конкурентной борьбе. Отметим, что именно внешние факторы влияют на принятие решения о централизации капитала. В более крупных компаниях даже создаются специальные подразделения, функции которых сводится к постоянному наблюдению как за внешней, так и за внутренней средой на рынке.

Так, по мнению Н.Б. Рудык и Е.В.Семенковой, принятие решения о совершении сделки централизации капитала в форме слияния или поглощения является одним из трудных финансовым решением в своей деятельности. Заметим, что процесс централизации не входит ни в одну из повседневных мероприятий ни одной компании.

Так, было замечено, например, что для осуществления слияния среднего масштаба необходимо совершить не менее 2000 действий и решить более 10000 задач. Можно сказать, что каждая компания осуществляет необходимые действия для централизации своими методами, поэтому нельзя сказать более точно, как и какие действия необходимо предпринять для проведения данного процесса. Но, несмотря на это, в научной литературе саму процедур сделок по централизации капитала принято разделять на определенные этапы. Таким образом, еще раз подчеркнем, что процесс централизации выступает одним из фундаментальных направлений 
экономической жизни, которая сложилась одновременно с появлением капиталистической системы. Изучением данного явления занимались многие ученые-экономисты. Но, можно отметить К. Маркса, которому удалось более полно разъяснить явление централизации в своем труде «Капитал». Именно его работа остается актуальной до сегодняшнего дня.

Маркс определил взаимосвязь между понятиями централизация и концентрация в их ключевых целях - увеличение размеров капитала. Но в это же время данные понятие нельзя приравнять друг к другу, ведь централизация процесс объединения существующих капиталов, а концентрация - процесс накопления за счет аккумулирования свободных денежных средств. Иначе говоря, для централизации источником роста является внешние составляющие, а для концентрации - внутренние.

За последние двадцать лет макроэкономическая значимость банковского сектора в нашей стране возросла, и на сегодняшний день занимает ключевое место в финансовой системе. Так, если на начало 2000 года отношение активов банковского сектора к ВВП составляло $32,6 \%$, то на начало 2019 года данный показатель составил $90,6 \%$, что практически в три раза больше значения в начале века. Национальный банковский сектор и экономика в целом подвергаются изменениям за последние годы. Это связано, прежде всего, с ограничительными мерами, которые вводятся странами ЕС, США и другими. Вследствие того, что протекают изменения в мировой экономике и нестабильное развитие отношений между ведущими странами мира, конкурентоспособность и стабильность банковской системы выступают ключевыми характеристиками.

Можно выделить несколько отличительных черт российской банковской системы. Во-первых, высокий уровень монополизации сектора. Например, это такие крупные банки как, Сбербанк и ВТБ, которые, к тому же функционируют при поддержке государства. Монополизация рынка становится угрозой для существования малых и средних кредитных организаций. Именно монополия приводит к неравной конкуренции - малых предприятия просто не могут вести борьбу за клиентов в условиях неравной конкуренции. Во-вторых, первая особенность обуславливает вторую немаловажную черту, а именно несовершенное законодательство, которое не исполняет Ф3 от 30.12.2001 «О защите конкуренции на рын- ке финансовых услуг». А следовательно, неисполнение закона препятствует развитию добросовестной конкуренции. В-третьих, российский банковский сектор характеризуется высокой степенью концентрацией. Это черта также свидетельствует о неравномерности распределения активов. В-четвертых, кредитные организации неравномерно распределены с географической точки зрения по территории страны. Этот факт обуславливает недостаточную обеспеченность ряда субъектов банковскими услугами и низкую конкуренцию в масштабах государства. В-пятых, низкое количество банковских отделений в расчете на 100 тысяч человек. В России на 1 тысяч жителей приходится в среднем 14 банковских отделений. Для сравнения: в Италии - 40 [3], в США - 30 [4]. В-шестых, небольшое представительство иностранных банков в стране. Россия стремится сохранить контроль над банковским сектором, именно поэтому число иностранных банков в нашей стране не так велико. Достаточно важным моментом, на который необходимо обратить внимание при оценке и анализе банковского сектора, это валютный курс. Если проследить за курсом рубля, то можно увидеть постепенное его снижение, что в основном связано с зачисткой банковского сектора.

Данный факт выступает причиной оттока национального капитала. Именно это оказывает негативное влияние на конкурентоспособность в банковском секторе. Отметим, что такое снижение капитала уменьшилось в период с 2015 по 2016 года, но, тем не менее, дальше заметен рост показателя, и уже в 2018 году показатель увеличился в 2,7 раза относительно предшествующему году. Согласно данным ЦБ, в 2019 году продолжилось сокращение внешних обязательств национальных банков. А именно временная остановка закупки валюты по бюджетному правилу на открытом рынке ЦБ для Минфина послужила причиной накоплению валюты на счетах.

Также отметим, что именно инфляционные риски создают достаточно большие сложности для банковской системы нашей страны. Так, за 2019 год уровень инфляции в стране составил $3 \%$, что много меньше по сравнению с 2015, но больше, чем в 2017 г. и практически близок к аналогичному показателю в 2017 году (см. рис.1).

Можно отметить, что ставка рефинансирования следует четко за уровнем инфляции. Так, уменьшение инфляции ведет к уменьшению ключевой ставки, что ведет к увеличению ак- 


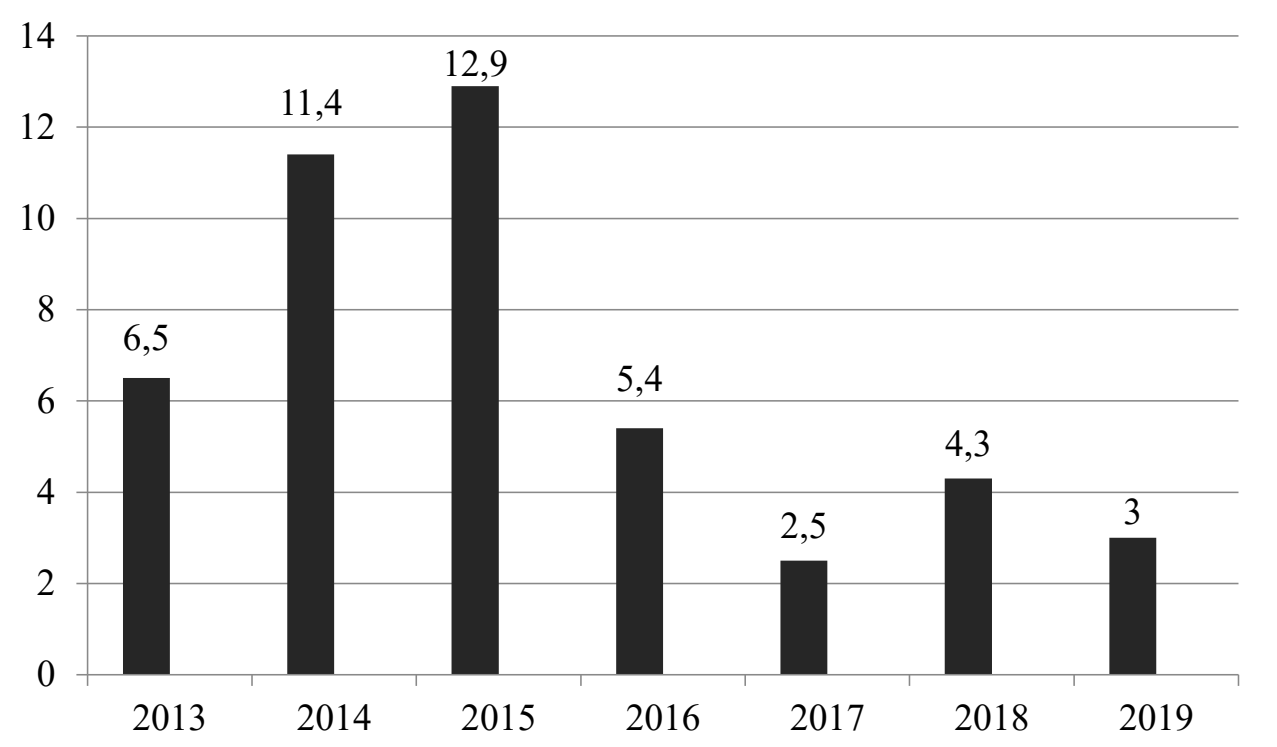

Рисунок 1. Годовое значение инфляции за 7 лет,\%

Источник: «Статистика и показатели» / Главная / Статистика / Инфляция по данным Росстат, [электронный ресурс] URL: https://rosinfostat.ru/ (дата обращения: 03.05.2020)

тивной деятельности во всех отраслях и непосредственно на банковском рынке. Посредством процедуры рефинансирования главный регулятор банковского сектора имеет возможность регулировать ликвидность банковского сектора. Именно для этого проводят снижение ключевой ставки и можно заметить снижение показателя с 17\% в 2015 году до 6,25\% в 2019 г. [8] Можно выделить одну из ключевых особенностей банковского сектора в России. Такой отличительной чертой выступает функционирования банков с государственным участием с одной стороны, и частных банков с другой стороны. Функция кредитных организаций, доля которых приходится на государство, заключается в развитии экономической сферы страны. У подобных организаций есть возможность использовать в роле основного пассива федеральный бюджет.

Говоря о преимуществах банковской системы в нашей стране, можно отметить, как и ресурсный потенциал, так и восприимчивость к технологиям, и рациональное регулирование. Но, помимо этого, недостаточно развитая инфраструктура, неизбирательный спрос и вялая конкуренция также присущи для нашего национального банковского сектора.

Как уже говорилось ранее, в 2014-2019 гг. была реализована политика по оздоровлению банковского сектора путем отзыва лицензий у банков. За этот период число участников рынка сократилось более чем вдвое - если на начало
2014 года по данным ЦБ РФ в стране действовало 923 кредитных организаций, то на середину 2019 года кредитных организаций стало 464 [9].

Как отмечалось Банком России, одной из основной причиной отзыва лицензии у кредитных организаций является высокорискованная бизнес-модель. Достаточно часто такая модель предусматривала кредитование проектов собственников банка за счет средств сторонних клиентов и соответствующую неадекватную оценку таких активов.

Отметим, что до дня отзыва лицензии у банков на осуществлении банковских операций, проводятся меры по предупреждению банкротства кредитных организаций. Это такие меры, как [10]:

1. Финансовое оздоровление;

2. Назначение временной администрации по управлению кредитной организацией

3. Реорганизация кредитной организации;

4. Меры по предупреждению банкротства кредитной организации.

В 2017 году был введен в действие новый механизм санации, предусматривающий передачу проблемного банка Фонду консолидации банковского сектора (ФКБС), подконтрольному Банку России. Данная схема предоставляет Банку России прямое участие в качестве инвестора. Согласно строй же схеме, санация осуществлялась Агентством по страхованию вкладов с привлечением внешних инвесторов. 
Оздоровление осуществляется путем решения проблемы с задолженностью пред кредиторами, с неликвидными активами, также оптимизируется система управления и руководства, сокращаются нерентабельные отделения и филиалы и внедряются более современные методы работы. Одним из распространенных методов оздоровления выступает санация в форме присоединения проблемного банка к крупному игроку на данном рынке. Так, в период с 2018-2019 гг. была проведена санация 15 банков в форме присоединения. Некоторые из банков, проходящие финансовое оздоровление (см. Таблицу).
Таким образом, проблемные банки присоединяют к более крупным, которые способны дать второй шанс. Такой способ оздоровления, с привлечением коммерческого банка-санатора называют кредитным. Банк России предоставляет санатору льготный кредит, с помощью которого и проводит финансовое оздоровление проблемного банка. Данная схема оздоровления, как правило, рассчитана на 10-15 лет, полное оздоровление наступает под конец, когда банк закрывает все проблемы, однако при наличии возможностей у банка-санатора, процедура может закончится значительно быстрее.

Таблица. Кредитные организации, реорганизованные в форме присоединения 2018-2019 гг.

\begin{tabular}{|c|c|c|c|c|c|c|c|}
\hline \multirow{2}{*}{$\begin{array}{l}\text { E } \\
\text { 三 } \\
\text { ol } \\
\text { 之 }\end{array}$} & \multicolumn{4}{|c|}{ Информация о присоединившейся КО } & \multicolumn{3}{|c|}{$\begin{array}{l}\text { Информация о КО, к которой } \\
\text { осуществлено присоединение }\end{array}$} \\
\hline & Наименование & Рег.№ & $\begin{array}{c}\text { Дата регист- } \\
\text { рации }\end{array}$ & $\begin{array}{c}\text { Дата } \\
\text { реоргани- } \\
\text { зации }\end{array}$ & Наименование & Рег.№ & $\begin{array}{c}\text { Дата регист- } \\
\text { рации }\end{array}$ \\
\hline 1 & Хованский & 2145 & 26.10 .1992 & 28.02 .2018 & Джей Энд Ти Банк & 3061 & 21.09 .1994 \\
\hline 2 & ВТБ24 & 1623 & 18.11 .1991 & 01.01 .2018 & ВТБ & 1000 & 17.10.1990 \\
\hline 3 & Рост Банк & 2888 & 10.06 .1994 & 02.07.2018 & Траст & 3279 & 27.11 .1995 \\
\hline 4 & Глобэкс & 1942 & 07.07 .1992 & 26.11 .2018 & Связь-Банк & 1470 & 20.05 .1991 \\
\hline 5 & Росевробанк & 3137 & 19.10.1994 & 12.11 .2018 & Совкомбанк & 963 & 27.11 .1990 \\
\hline 6 & СКИБ & 3329 & 27.05 .1998 & 12.11 .2018 & Совкомбанк & 963 & 27.11 .1990 \\
\hline 7 & Банк Диджитал & 2827 & 10.05 .1994 & 01.01 .2019 & ФК Открытие & 2209 & 15.12 .1992 \\
\hline 8 & Бинбанк & 323 & 25.06 .1990 & 01.01 .2019 & ФК Открытие & 2209 & 15.12 .1992 \\
\hline 9 & Автовазбанк & 23 & 16.11 .1988 & 07.03 .2019 & Траст & 3279 & 27.11 .1995 \\
\hline 10 & Балтийский банк & 128 & 11.1989 & 13.05 .2019 & Альфа-банк & 1326 & 20.12 .1990 \\
\hline
\end{tabular}

Источник: Вестник Банка России № 30 (2082) от 06.06.2019, [Электронный ресурс]. URL: https://cbr.ru/Content/Document/ File/71888/stat_lic_2018.pdf (дата обращения: 06.08.2020)

\section{Библиографический список}

1. Борисов, Е. Ф. Экономическая теория: учебник / Е. Ф. Борисов.- М.: ТК Велби Из-во «Проспект», 2008.-544 с.

2. «Большая советская энциклопедия»/ Централизация капитала [электронный ресурc] URL: https:/gufo.me/ $\mathrm{dict/bse} \mathrm{(дата} \mathrm{обращения:} \mathrm{01.04.2020)}$

3. Banca d'Italia - Base dati statistica / Statistica / Banche, istituzioni finanziarie, moneta e mercato finanziario / Banche e istituzioni finanziarie / Report / Banche e istituzioni finanziarie: articolazione territorialeStatistiche [электронный ресурc] URL: https://www.bancaditalia.it/ (дата обращения: 20.04.2020)

4. Knоета - Мировая статистика / данные и статистика США / Экономика / Финансовый сектор » Доступ к финансовым ресурсам [электронный ресурc] URL: https://knoema.ru/ (дата обращения: 05.05.2020)

5. Михайлов А. М. Дивидендная политика российских акционерных обществ как фактор формирования акционерного капитала // Вестник Самарского государственного экономического университета. 2020. № 3 (185). C. $9-16$

6. Михайлов А. М. Транснациональные банки: реализация экономических и институциональных интересов // Экономические науки. 2019. № 176. С. 12-16

7. Михайлов А.М., Искандаров Т. С., Городнов В. А. Роль фондового рынка в финансирование экономики РФ // Экономические науки. 2019. № 173. С. 22-26 
8. Официальный сайт Центрального Банка РФ/ Базы данных / Ключевая ставка [электронный ресурс] URL: https://cbr.ru/ (дата обращения: 03.05.2020).

9. Официальный сайт Центрального Банка РФ/ Статистика/ Банковский сектор/ Информация о банковской системе РФ, [Электронный ресурc]. URL: https://www.cbr.ru/ (дата обращения: 08.05.2020)

10. ФЗ от 26.10.2002 № 127-ФЗ «О несостоятельности (банкротстве)» (дата обращения: 08.05.2020) 